San Jose State University

SJSU ScholarWorks

Master's Theses

Master's Theses and Graduate Research

Summer 2015

\title{
The Effect of Distractions on Task Performance and Enjoyment as Moderated by Regulatory Fit
}

Kimberly Leung

San Jose State University

Follow this and additional works at: https://scholarworks.sjsu.edu/etd_theses

\section{Recommended Citation}

Leung, Kimberly, "The Effect of Distractions on Task Performance and Enjoyment as Moderated by Regulatory Fit" (2015). Master's Theses. 4595.

DOI: https://doi.org/10.31979/etd.2kvf-5j6a

https://scholarworks.sjsu.edu/etd_theses/4595

This Thesis is brought to you for free and open access by the Master's Theses and Graduate Research at SJSU ScholarWorks. It has been accepted for inclusion in Master's Theses by an authorized administrator of SJSU ScholarWorks. For more information, please contact scholarworks@sjsu.edu. 
THE EFFECT OF DISTRACTIONS ON TASK PERFORMANCE AND ENJOYMENT AS MODERATED BY REGULATORY FIT

\author{
A Thesis \\ Presented to \\ The Faculty of the Department of Psychology \\ San José State University \\ In Partial Fulfillment \\ of the Requirements for the Degree \\ Master of Science
}

Kimberly A. Leung

May 2015 
(C) 2015

Kimberly A. Leung

ALL RIGHTS RESERVED 
The Designated Thesis Committee Approves the Thesis Titled

THE EFFECT OF DISTRACTIONS ON TASK PERFORMANCE AND ENJOYMENT AS MODERATED BY REGULATORY FIT

by

Kimberly A. Leung

APPROVED FOR THE DEPARTMENT OF PSYCHOLOGY

SAN JOSÉ STATE UNIVERSITY

May 2015

Dr. Megumi Hosoda

Department of Psychology

Dr. Howard Tokunaga Department of Psychology

Dr. Harriet Pila

Department of Psychology 


\section{ABSTRACT \\ THE EFFECT OF DISTRACTIONS ON TASK PERFORMANCE AND ENJOYMENT AS MODERATED BY REGULATORY FIT}

by Kimberly A. Leung

Every day, distractions keep people from maintaining focus and productivity. Music, in particular, is a distraction that can easily disrupt individuals mentally and physically. However, what if common distractions like music had the power to motivate people towards a goal rather than deter them from it? Regulatory Focus Theory offers an explanation for how this is possible. It posits two motivational foci: promotion and prevention. If individuals are promotion-focused, they seek positive outcomes, and if individuals are prevention-focused, they try to avoid negative outcomes.

The current study tested the assumption that avoiding distractions during goal pursuit matched the behavior of someone with a prevention focus better than someone with a promotion focus and simply being in a prevention focus when completing a task could increase an individual's task enjoyment and performance when distractions were present. Participants were first given a questionnaire to determine their regulatory focus. Then their task was to solve math problems in the presence or absence of music which served as the distraction. The results of 150 participants did not support the hypotheses and showed that, regardless of whether a distraction was present or not, promotionfocused participants performed better and enjoyed the task more than their preventionfocused counterparts. 


\section{ACKNOWLEDGEMENTS}

This thesis would not have been possible without the collaborative effort of my thesis committee and the support of my family and friends. First and foremost, I would like to express my sincere gratitude and appreciation for Dr. Megumi Hosoda. There are not enough thanks in the world for how grateful I am for your time and dedication in this process. Thank you for this opportunity and for the constant motivation to persevere whenever I struggled. Second, thank you to Dr. Howard Tokunaga for your words of wisdom and guidance that I could apply not only to my thesis, but to life. You taught me to always consider different perspectives, and when there was a difference of opinion, that it was important for me to maintain ownership. Third, I would like to thank Dr. Harriet Pila for sparking my interest in the field when I took your class, "Introduction to Industrial/Organizational Psychology.” A special thanks to my colleague, Zakwan Salahieh, for all the weekend trips to the library and for your never-ending support and encouragement.

Thank you to my parents for raising me to believe that I can achieve anything I put my mind to and to my five siblings for helping me relax and sharing a laugh when I was stressed. I also want to thank my loving boyfriend and my close friends for calming my tears and reminding of the importance of taking a break every once in a while. Thank you for your patience and understanding when I could not hang out or when I just wanted to sleep. I would not have been able to accomplish this thesis without having such a strong foundation of support and I thank all of you for your full confidence in my ability. I am eternally grateful and blessed to have all of you in my life. 


\section{TABLE OF CONTENTS}

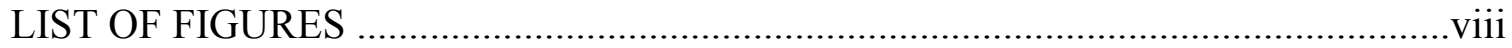

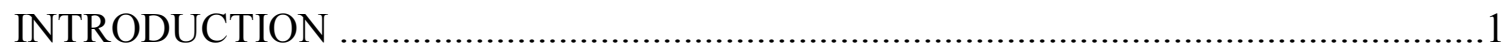

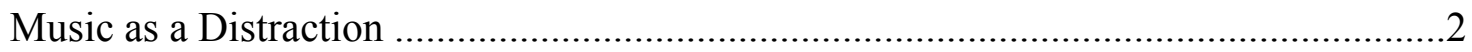

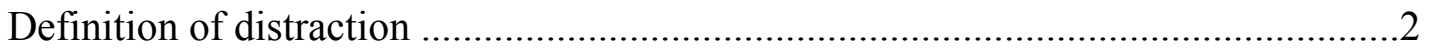

Distracting characteristics of music ....................................................................

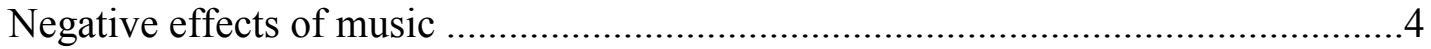

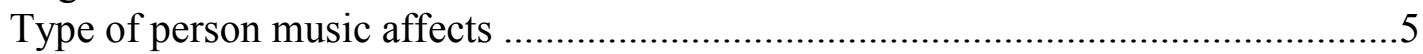

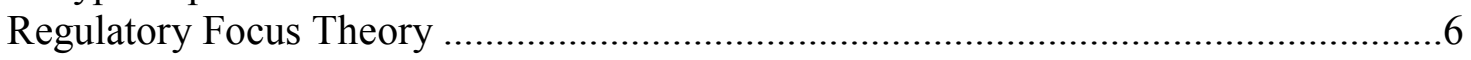

Definition of regulatory focus .........................................................................6

Regulatory fit and its effect on enjoyment ……………...................................

Regulatory fit and its effect on task performance ……..........................................

Benefit of prevention focus when concerned with goal pursuit ................................ 9

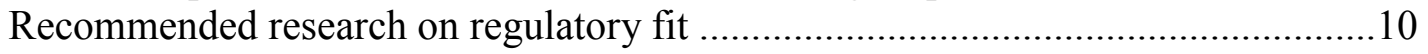

Regulatory fit as a moderator ……………......................................................10

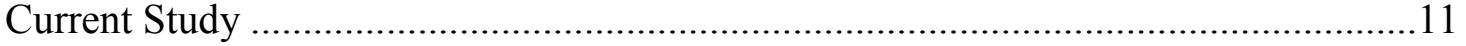

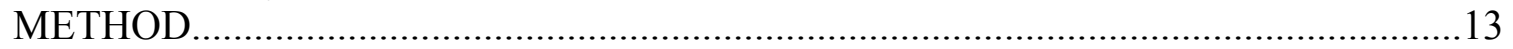

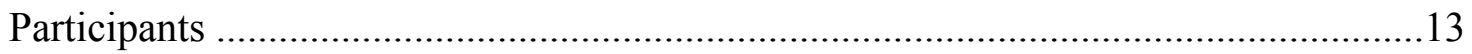

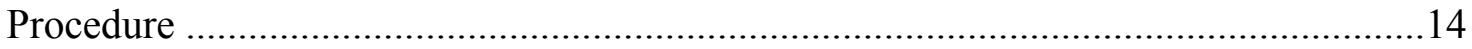

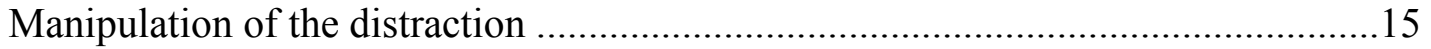

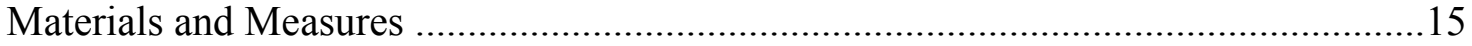

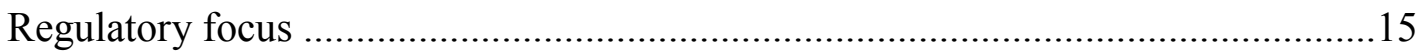

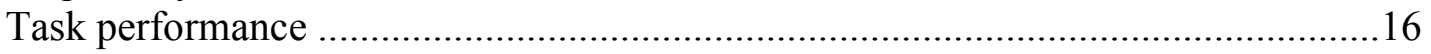

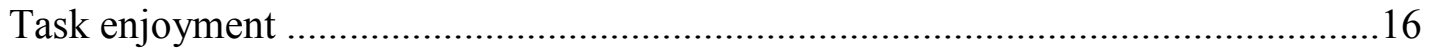

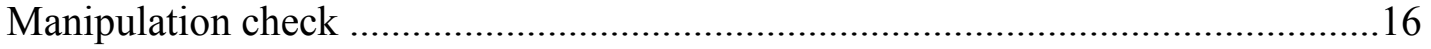

Demographic information .............................................................................17

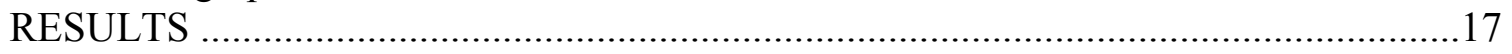

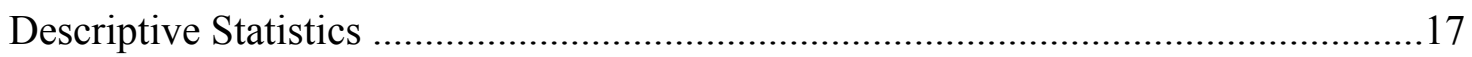

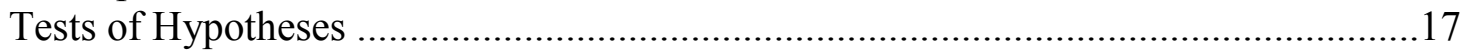

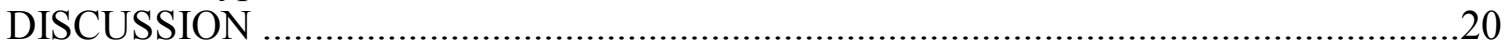

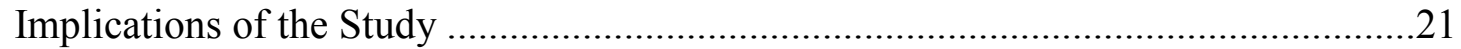

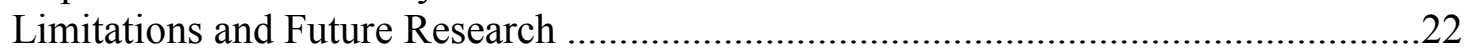

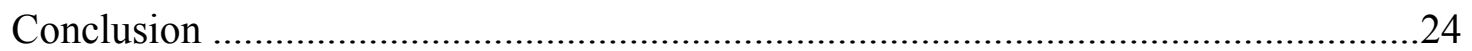

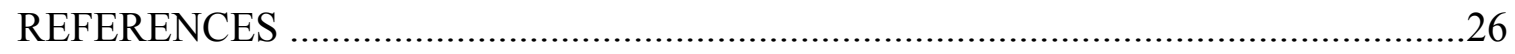

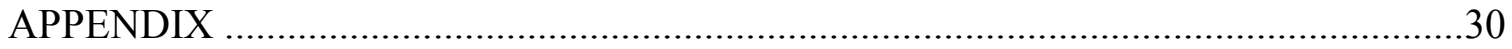

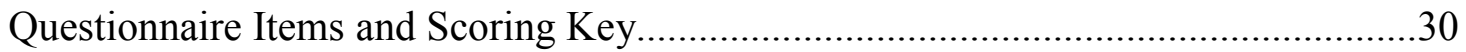




\section{LIST OF FIGURES}

Figure 1. Task performance by regulatory focus and distraction ..............................18

Figure 2. Task enjoyment by regulatory focus and distraction ................................20 


\section{Introduction}

Distractions are a part of everyday life. Some common examples include receiving a text message while driving, a Facebook notification popping up on one's news feed while typing a report, or being invited to see the latest Marvel movie when there are chores that need to be done. Although it may seem difficult to stay focused with such distractions, people employ various strategies to help them complete the task at hand or to reduce the distraction. A common strategy in the workplace is simply to move to a different work space in order to avoid the distraction. For example, students may go to the library or a café to work on homework in order to avoid distractions at home.

However, if people knew how to deal with the distractions, maybe the distractions would become less distracting or, even possibly, motivating.

Being prepared for distractions is a good strategy; however, avoiding distractions may potentially exhaust one's energy cognitively and physically, which could make goal attainment difficult. While some people are focused on how generally to avoid distractions, some people can perceive distractions as a potential motivator. The current study expanded on this idea by focusing on self-regulation and the effects of auditory distraction, specifically background music. Music has been identified as one of the more common auditory distractions in the workplace (e.g., Smith, 2012). As such, background music was chosen in order to simulate a common distraction in a typical office environment such as the situation where music is being played in a neighboring cubicle. The effect of music on task performance and the effect of regulatory fit within Regulatory 
Focus Theory (a self-regulation model) are presented in the following sections. The hypotheses that were tested in the present study are also introduced.

\section{Music as a Distraction}

Definition of distraction. According to Merriam-Webster (2014), a distraction is something that makes it hard for one to think or pay attention. The current study was primarily focused on the implications of distractions in an office setting. Some common examples of auditory distractions in the workplace include people chatting, loud phone calls, instant messaging sounds, music, office machines, televisions, and outside noise like construction or singing birds (Smith, 2012). The word distraction has a negative connotation because it is generally thought of as being detrimental to productivity. Loss in productivity and efficiency has the potential to be costly for all parties involved in an organization (Scharf, 1995). According to Juneja (2011), auditory distractions that originate from the surrounding work environment can do harm to an organization, especially in open-plan offices. Distractions can negatively influence job performance (e.g., loss in productivity), behavior (e.g., acting out towards others from frustration), and health (e.g., unexpected hospital visit due to stress buildup). BASEX, a New York research firm, estimated that distractions cost the U.S. economy $\$ 588$ billion per year (Spira \& Feintuch, 2005). BASEX also reported that workers lost an average of 2.1 hours per day due to constant interruptions and recovery time, therefore losing $28 \%$ of their productivity, and that a 30 -second interruption could result in a worker taking 20 minutes to get back into the flow of work ("Too Much Technology is Cutting Productivity," 2008). 
Auditory distractions include a wide range of sounds and noises, but background music in particular seems to be a popular distraction (Smith, 2012). However, whether background music has an overall positive or negative effect is controversial. Research has indicated that music has both adverse and beneficial effects (Shih, Huang, and Chiang, 2009). The impact of background music before and during an attention test was compared to the impact of no music at all (Shih et al.). Participants scored higher on the attention test when music was played before the test compared to when music was not played. However, students who took the test concurrently with music had the lowest mean score, suggesting that music during the test had an adverse effect on performance.

Kämpfe, Sedlmeier, and Renkewitz (2011) conducted a meta-analysis and found that background music had a positive effect in sports performance and a negative effect on reading comprehension and memory. Thus, the effect of background music seems to depend upon the type of task being studied. The current study was focused mainly on task performance typical to the workplace including reading comprehension and memory; therefore, music is defined as a negative distractor in this study.

Distracting characteristics of music. It is important to note that the distracting element in music is not just the presence of music, but also the type of music being played. Cantor (2013) found that popular music usually interferes with problem solving or highly cognitive, complex tasks. In the current study, certain aspects of music (e.g., tonal vs. atonal, vocal vs. instrumental, hip hop vs. classical) were taken into consideration when compiling a list of songs to be used. These songs are inherently distracting due to their popularity. Studies that were focused on comparing specific 
components of music were taken into account when building the song profile to help illustrate the kinds of music that might be more detrimental than others. For instance, Pearsall (1989) found that those provided with tonal background music had significantly lower listening comprehension compared to those provided with atonal or no background music, indicating that tonal music was more distracting.

Likewise, Salamé and Baddeley (1989) found vocal music was more disruptive than instrumental music on short-term memory. Shih, Huang, and Chiang (2012) also found adverse effects on participant concentration and attention when listening to music with lyrics. The studies reviewed above were aimed at breaking down the specific components of music that may be more distracting, but it might be equally important to consider the genre of music being played as well. Unless it is classical or instrumental, most music popularized by people today has lyrics and varying tempos that seem to be the most distracting. The five songs used in the current study were selected based on these findings.

Negative effects of music. Music is designed to attract attention, but it is interesting to note the impact a sound can make on task performance. Auditory distractions can negatively affect numerous everyday activities, including learning a new skill or piece of information (iPods and Learning: Not Always a Good Mix, 2006). Even if a distraction does not hinder the level of learning, it may affect the ability to recall knowledge at a later time (Foerde, Knowlton, Poldrack \& Smith, 2006). The notion that listening to sound takes away attention may be due to the brain being trained to process sound changes before other stimuli (Fraser \& Bradford, 2013). 
Type of person music affects. It is easy to say that distractions affect everyone, but with the appropriate research, it may be possible to distinguish who is affected more than others. Most statistical analyses are based on averages; individual factors that may be important then can be overlooked. In the study by Shih et al. (2009) where music was played before and during a test, there was another interesting result in addition to their overall findings. Although the mean score of the group that took the test while listening to music was lower than the mean score of the group that listened to music before testing, the individual scores for the group with music during testing varied widely. The variability in task performance might have been due to the presence of individual differences that were not considered.

More research should be directed at examining how music affects the performance of different types of people (e.g., different personality traits or motivational processes). For instance, Furnham and Bradley (1997) tested the effects of music on the performance of introverts and extraverts with a memory test. They then measured participant reading comprehension as well as their immediate and delayed recall. When music was played during the memory test, both groups showed detrimental effects with regard to immediate recall. Moreover, introverts exposed to music yielded the lowest results in reading comprehension and delayed recall among both introverts in silence and extraverts exposed to music. Similarly, Furnham and Strbac (2002) found that, compared to extraverts, introverts' performance on complex cognitive tasks (i.e., reading comprehension and arithmetic) was more negatively affected by distractors like music, background television, and office noise. Studies like these two help build a profile of a 
specific type of person, based on traits and behaviors, who may be less susceptible to distractions.

In a related study, Doyle and Furnham (2012) examined whether the effect of music on task performance varied as a function of an individual's creativity level. Creative individuals performed better than their non-creative counterparts when music was played. Furthermore, creative individuals who listened to music while studying reported lower levels of distraction. These findings support the notion that personality traits moderate the effects of music on performance.

In examining how individual human differences influence the effects of music on performance, it is also important to study motivational processes that steer people's decision making. Higgins' (1997) Regulatory Focus Theory explains how the type of decision-making process can determine if people deal with distractions positively or negatively and therefore affect their performance. Regulatory Focus Theory is described in more detail in the following section and the notion of regulatory fit is also introduced.

\section{Regulatory Focus Theory}

Definition of regulatory focus. Self-regulation is a goal-directed process whereby people regulate their behaviors and cognitions in order to attain their goals (Lee, 2012). Regulatory Focus Theory offers an explanation for how people find different ways to achieve the same goal (Förster \& Werth, 2009). The theory consists of two motivational states or "self-guides:" (a) ideal self-guide, which refers to individuals' perception of behavior that someone (themselves or someone else) would like them ideally to possess and that fosters a desired state of hope or aspiration; and (b) ought self- 
guides, which refers to individuals' perception of duties or responsibilities (Higgins, 1997; 1998).

Having an ideal self-guide is also known as having a promotion focus; individuals demonstrating this regulatory state are seekers of positive outcomes and are concerned with nurturance and accomplishment. They make decisions based on the presence or absence of gains. In other words, they are more sensitive to the difference between " 0 " and "+1" (attainment). In contrast, those enacting an ought self-guide are known as prevention-focused individuals who make decisions based on the presence or absence of losses. That is, they are sensitive to the difference between " 0 " and "-1" (maintenance) and try to avoid negative outcomes by conducting themselves with vigilance and maintaining security. For instance, a person exhibiting a promotion focus may think, "I will work hard in order to get a promotion and be financially secure," whereas a person exhibiting a prevention focus might think, "I will work hard so I do not end up on the street without an income." Ultimately, they achieve the same goal of working hard but with different motivational strategies. Each motivational process is a distinct way to embrace pleasure and avoid pain. Nurturance and security are both necessary instincts for survival so each regulatory focus is available to everyone, although with varying accessibility (Higgins, 2009).

Regulatory fit and its effect on enjoyment. There are three main elements of goal pursuit: 1) the goal, 2) the person's motivational orientation (regulatory focus), and 3) the manner or means of the goal pursuit (Higgins, 2009). According to Regulatory Focus Theory, regulatory fit is the "fit" or match between a person's regulatory focus 
(promotion or prevention) and the manner of the goal pursuit (promotion-framed or prevention-framed). Promotion-framed refers to an environment that facilitates a promotion focus while a prevention-framed refers to an environment that facilitates a prevention focus. For example, participants primed to consider their duties and obligations enjoy prevention-framed tasks (e.g., "avoid missing any classes") more than promotion-framed tasks (e.g., "attend all classes"), whereas the reverse is true for participants primed to consider their hopes and aspirations (Freitas \& Higgins, in press). Regulatory fit is when the situation sustains (vs. disrupts) a person's motivational orientation. In addition, regulatory fit does not change a person's motivational orientation but merely enhances it (Higgins, 2000). Fit makes people "feel right" about and engage more in what they are doing, leading to greater perceptions of goal value and more effective performance (Higgins, 2009). In other words, it seems natural to feel positively about reaching one's goal under preferred circumstances.

Regulatory fit and its effect on task performance. The application of regulatory fit and its positive influence on task performance has been widely researched. Study results indicate that regulatory fit increases motivation and performance in various activities, including receiving positive feedback (Jarzebowski, Palermo, \& van de Berg, 2012), classroom engagement (Rodriguez, 2012), and working with a role model with the same motivational orientation (Lockwood, Jordan, \& Kunda, 2002). For example, Shah, Higgins, and Friedman (1998) gave college students an anagram task along with instructions that were framed as either promotion-focused (find more than $90 \%$ of all possible words and receive an extra dollar) or prevention-focused (do not miss more than 
$10 \%$ of all possible words or one dollar will be deducted). Participant performance was higher in situations of regulatory fit (i.e., person with promotion focus in a promotionframed task or person with prevention focus in a prevention-framed task) than situations of regulatory non-fit (e.g., person with promotion focus given a prevention-framed task). Shah et al.'s study is one of many that emphasized the power of regulatory fit and the strong implications it can have especially when it pertains to goal pursuit.

Benefit of prevention focus when concerned with goal pursuit. As previously mentioned, prevention-focused and promotion-focused people see the same goal but approach it in two different ways. For example, with regard to deadline behavior, those who exhibit a promotion focus view deadlines in the future, while prevention-oriented people initiate their goals earlier (Woltin \& Jonas, 2012). According to Freitas, Liberman, Salovey, and Higgins (2002a), this result occurred because people with a prevention focus see a goal as a necessity, whereas those with a promotion focus see it as one of many opportunities for accomplishment, thereby minimizing its urgency.

Other studies support this theory and show how having a prevention focus can help regulate the way people approach goal attainment under difficult circumstances. This is similar to the famous study by Patterson and Mischel (1976) where preschoolers were instructed to do a repetitive peg board task with a particular "Clown Box" tempting them to play with him. In the promotion condition, when the Clown Box asked them to play with him, children were prompted to look away and say "I am going to look at my work." In the prevention condition, when the Clown Box initiated play, children were instructed to look away and say "I am not going to look at Mr. Clown Box." The last 
condition was where children were not given any instructions. The children who were in the prevention condition accomplished more work overall, whereas those in the promotion condition did not perform any better than those who did not receive any prompting.

Recommended research on regulatory fit. Patterson and Mischel (1976) suggested future research on self-regulation and how it might facilitate performance in stressful situations. Bakker, Schaufeli, Leiter, and Taris (2008) also recommended looking into an individual's regulatory focus and how regulatory fit would affect work engagement. They advocated research that measured whether engagement was highest when there was regulatory fit. For example, would a promotion-focused employee work better in an environment emphasizing growth and resources? Likewise, would a prevention-focused employee work better in an environment emphasizing duties and demands? More research on regulatory fit in the workplace could lead to strategies that help increase job engagement and company success. However, studies like those previously mentioned were focused on the direct effect of regulatory fit on an outcome. In the current study, we hoped to expand on this idea by utilizing regulatory fit as a moderator of the relationships between distractions and task performance and enjoyment.

Regulatory fit as a moderator. While one focus has not been found to be better than the other, it has been predicted that having a prevention focus yields better results when resisting temptation. Freitas, Liberman, and Higgins (2002b) measured student performance and enjoyment of solving math problems in the presence or absence of video advertisements (i.e., distractions) by looking at the moderating effect of 
participants' self-regulation process. Although there are several existing theories on selfregulation, Freitas et al. (2002b) thought that Regulatory Focus Theory might help people cope with distractions better than other theories.

Based on the assumption that those with a prevention focus resist temptation better than those with a promotion focus, Freitas et al. (2002b) hypothesized that in the presence of a distraction, people given a prevention-framed task perform better than people given a promotion-framed task. They found that when subjects were shown video clips of advertisements, those primed with a prevention orientation outperformed and enjoyed solving math problems more than those with a promotion focus. Similarly, the reverse was true when distractions were omitted. Compared to prevention-focused individuals, promotion-focused individuals performed better and enjoyed the task more with no distractions. The results suggest that prevention-focused participants who had to resist the distraction enjoyed their task more than prevention-focused participants who did not. Despite an abundance of research on regulatory fit, there is limited research on how an individual's regulatory focus influences the effects of distractions on performance. Freitas et al.'s (2002b) study seems to be the only one of its kind that was focused on the moderating effect of regulatory fit on the relationship between visual/auditory distractions and task performance with the inclusion of task enjoyment.

\section{Current Study}

Different behavioral tendencies between people who are prevention-focused and those who are promotion-focused are widely discussed in the research on Regulatory Focus Theory. The effect of these tendencies on motivation and performance should be 
explored further in order to build upon the research that is dedicated towards improving productivity in the workplace. Minimizing the negative effect of distractions might be one of the key ways a company maintains success (e.g., installing designated quiet rooms, limiting access to social media). By taking the type of person into consideration, a potential distraction at work might turn out to be a motivator.

The current study was focused on the relationship between distractions and task performance using the same assumption as used by Freitas et al. (2002b), specifically that avoiding obstacles was favored by a person with a prevention focus rather than a promotion focus. Furthermore, Freitas et al. (2002b) proposed that even without priming participants with particular strategies to deal with distractions, simply being in a prevention focus (vs. promotion focus) could increase one's task performance and enjoyment when distractions are present. However, there are a couple of key differences between the experimental design of Freitas et al. (2002b) and the current study.

Although Freitas et al. (2002b) did not propose distinct strategies to deal with the impending distractions for participants of either focus, participants were still primed with a short essay that increased the accessibility of participants' ideal or ought self-guides, thereby enhancing their promotion or prevention focus. In the workplace, not every assignment or project can be controlled or conducted in this manner. In the current study, this type of priming was omitted in order to reflect realistic work situations where work is given at face value. The reason Freitas et al. (2002b) included indirect priming of a promotion state or prevention state was that their definition of regulatory fit was a match between the indirect priming task (i.e., the essay framed either promotion or prevention) 
and the condition of the experiment (i.e., distraction present or absent). In the current study, however, regulatory fit was defined as the match between participants' innate focus (calculated using the Regulatory Focus Questionnaire) and the condition of the experiment. Both are standard forms of regulatory fit because the participants' state of focus was matched with the state of the surrounding condition. Like Freitas et al. (2002b), the main goal of this study was to measure the influence regulatory fit has on the distracting effect of music on task performance and enjoyment. Therefore, the following hypotheses were tested in the present study:

Hypothesis 1: The effect of distraction on task performance is moderated by the type of regulatory focus such that prevention-focused individuals perform better than promotion-focused individuals when music is present during their task; promotionfocused individuals perform better than prevention-focused individuals when music is omitted during their task.

Hypothesis 2: The effect of distraction on task enjoyment is moderated by the type of regulatory focus such that prevention-focused participants enjoy the task more than promotion-focused participants when music is present during their task; promotionfocused participants enjoy the task more than prevention-focused participants when music is omitted during their task.

\section{Method}

\section{Participants}

The sample included a total of 150 San José State University students. However, only 149 (50 male and 99 female) were included in the analysis as one of the participants 
had a null orientation (neither promotion nor prevention). The participants were part of an introductory psychology class where research participation was a requirement. Their ages ranged from 18 to 62 years old $(M=19.60, S D=4.45)$ with 18 -year-olds making up $46 \%$ of the sample. Forty-one percent were Asian $(n=61), 27 \%$ were Latino/a $(n=41)$, $13 \%$ were Euro-American/Caucasian $(n=19), 4 \%$ were African American $(n=6), 5 \%$ were mixed race $(n=7)$, and $10 \%$ listed other ethnicities $(n=15)$. All participants were required to have normal or corrected-to-normal hearing in order to participate in the study.

\section{Procedure}

Each experimental session was run with a single participant. It was held in a small room (5' x 6') located on campus in Dudley Moorhead Hall. There were no windows and only a chair and a table inside. At the beginning of each session, the experimenter informed the participant that the study was about working with distractions and directed him or her to complete the consent agreement. The experimenter then assigned the questionnaire designed to measure regulatory focus. The participant was instructed to flip the questionnaire over when it was complete. The next task was a demographic questionnaire sheet. Once complete, the experimenter distributed the math quiz and recited the following instructions:

"You will have 15 minutes to complete the following math assignment. During the task, music may or may not play in the background. If music does play, simply ignore it and focus on solving the math problems. Please read the directions carefully. Answer each question as quickly and as accurately as you can. You may begin." 
Each participant was randomly assigned to one of the two experimental conditions: the distraction condition (music played in the background) or the control condition (no music was played). While participants were working on the math quiz, the experimenter determined the participant's regulatory focus by scoring his or her answers on the Regulatory Focus Questionnaire, the first task of the experiment. Once the participant completed the math quiz or after 15 minutes had elapsed, the test was collected and a follow-up survey designed to measure the enjoyment of the task and distraction was distributed. After completion of the follow-up survey, the participant was provided with a written debriefing statement.

Manipulation of the distraction. In the distraction condition, music started to play 1 minute after beginning the math task. A handheld speaker was previously placed on the desk and played a set playlist at $80 \mathrm{~dB}$, as this level was found to be distracting (Wolfe, 1983). The playlist included five songs that were popularized to appeal to the college youth demographic: "Turn Down for What" by Lil Jon, "Fancy" by Iggy Azalea, "Dark Horse" by Katy Perry, "Problem" by Ariana Grande, and "Selfie" by The Chainsmokers. They were played in the same order for each music condition. In the control condition, no music was played.

\section{Materials and Measures}

Regulatory focus. Regulatory focus was determined using Higgins' (1997) Event Reaction Questionnaire, which consisted of 11 items that measured how frequently specific life events occurred in a participant's life. Items were measured on a 5-point scale $(1=$ never or seldom $/$ certainly false, $5=$ very often $/$ certainly true $)$. Sample items 
include "Do you often do well at different things that you try?" and "I feel like I have made progress toward being successful in my life." Using the scoring key created by Higgins (1997), participants' answers to each question determined a promotion score and a prevention score. Out of the 11 items, the promotion score was the average of responses to six questions and the prevention score was the average of responses to five separate questions. The overall regulatory focus was the difference between the promotion score and the prevention score. If the score was a positive number, the participant was in a promotion state of mind. Likewise, if the score was a negative number, the participant was in a prevention state of mind. If there was a score of zero, the overall focus was null, which was the case with one participant.

Task performance. Task performance was measured in terms of the number of correct answers to 15 math problems that were typical questions found on the SAT's. Possible scores ranged from 0 to 15.

Task enjoyment. In order to measure task enjoyment, participants were asked to rate two questions on a 5 -point Likert scale $(1=$ not at all, $5=$ extremely $)$. The two questions measuring task enjoyment $(r=.66, p<.001)$ were "How interesting was it for you to solve the math problems?" and "How much did you enjoy solving the math problems?" The overall task enjoyment score consisted of the averages of these two items. A higher score indicated more enjoyment of the task.

Manipulation check. In order to measure enjoyment of the distraction, participants were asked to rate two questions on a 5-point Likert scale $(1=$ not at all, $5=$ extremely). The two questions on the follow-up survey assessed the enjoyment of the 
distraction: "How interesting did you think the music was?" and "How much did you enjoy listening to the music?" These questions were only asked to participants who were assigned to the music condition. Finally, participants were asked to rate the difficulty of the task ("How difficult were the math problems?" This question was rated on a 5-point Likert scale $(1=$ very easy, 5 = very hard $)$.

Demographic information. Demographic information of participants was measured in terms of gender, age, and ethnicity.

\section{Results}

\section{Descriptive Statistics}

Based on the scoring key, there were 96 promotion-focused and 53 preventionfocused individuals. The number of items correctly solved ranged from 0 to 13 , with a mean of $5.95(S D=2.70)$, showing a normal distribution. Participants reported the average difficulty level of the task to be $2.95(S D=.70)$ on a 5-point scale, which indicated that participants believed the questions to be fair. The mean for task enjoyment was $2.85(S D=.96)$. Among those who listened to music, $(M=3.04, S D=1.10)$ participants seemed to enjoy the task as much as the distraction (i.e., music).

\section{Tests of Hypotheses}

Figure 1 shows the mean task performance as a function of regulatory focus orientation and the presence of distraction. Hypothesis 1 stated that prevention-focused individuals would perform better than promotion-focused individuals when music was present during their task but that promotion-focused individuals would perform better than prevention-focused individuals when music was omitted during their task. The 
hypothesis was tested using a 2 (regulatory focus: promotion-focused vs. preventionfocused) x 2 (distraction: music vs. no music) between-subjects analysis of variance (ANOVA). The results of the ANOVA showed no interaction between regulatory focus and distraction, $F(1,146)=.59, p=.45, \eta^{2}=.004$; nor a main effect for regulatory focus, $F(1,146)=.65, p=.42, \eta^{2}=.004$, or distraction, $F(1,146)=.07, p=.79, \eta^{2}=.00$. The results show that there was no significant difference between the mean scores of prevention-focused $(M=5.96, S D=2.63)$ and promotion-focused individuals $(M=5.98$, $S D=2.85$ ) when no music was played. When music was played, promotion-focused individuals performed slightly better $(M=6.21, S D=2.52)$ than those who were prevention-focused $(M=5.48, S D=2.77)$, but this difference was not statistically significant. These results show that Hypothesis 1 was not supported; in fact, the results indicated the opposite of what had been originally predicted.

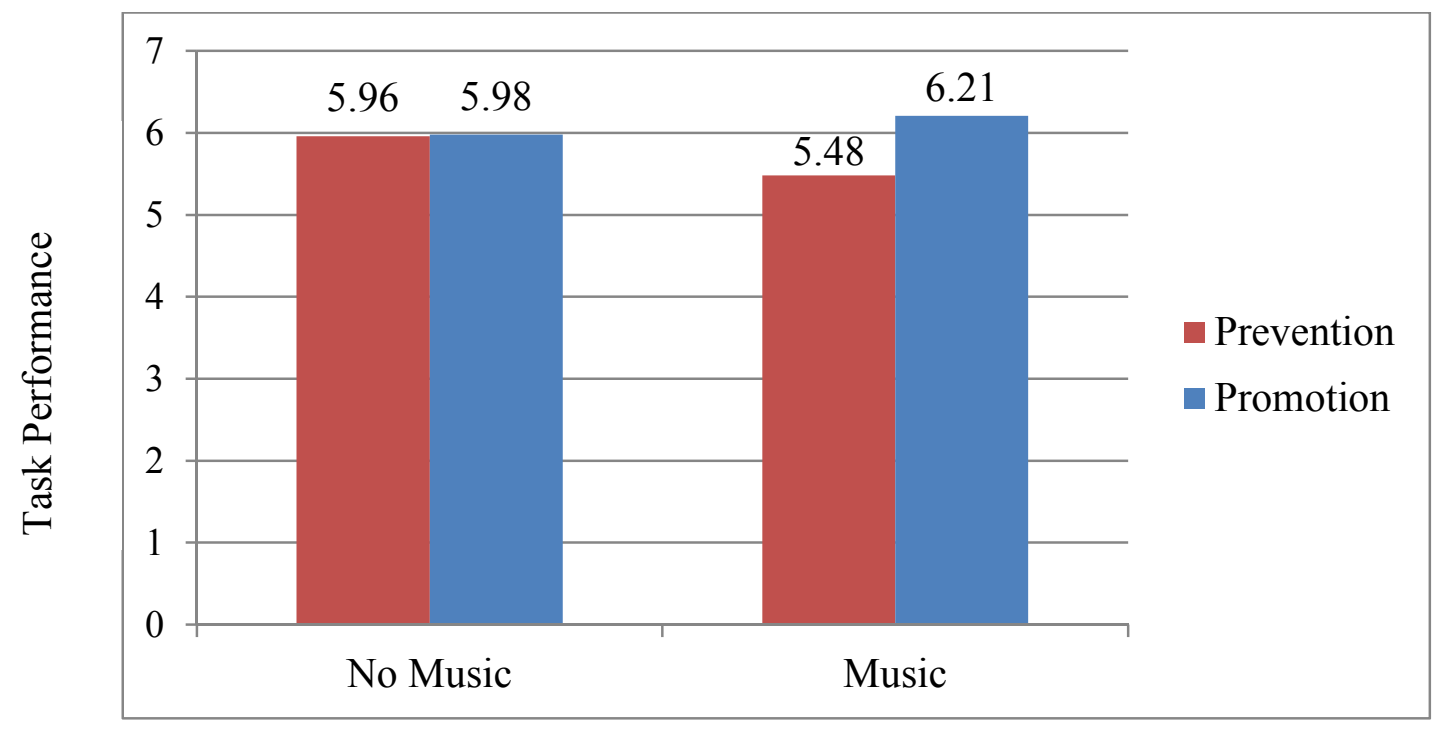

Figure 1. Task performance by regulatory focus and distraction Hypothesis 2 stated that prevention-focused participants would enjoy the task more than promotion-focused participants when music was present during their task but 
that promotion-focused participants would enjoy the task more than prevention-focused participants when music was omitted during their task. Figure 2 shows the mean task enjoyment as a function of regulatory focus orientation and the presence of distraction. A 2 (regulatory focus: promotion-focused vs. prevention-focused) x 2 (distraction: music vs. no music) between-subjects analysis of variance (ANOVA) was also used to test the hypothesis. The results of the ANOVA revealed no interaction between regulatory focus and distraction, $F(1,144)=.53, p=.47, \eta^{2}=.004$; nor a main effect for regulatory focus, $F(1,144)=1.84 ., p=.177, \eta^{2}=.013$, or distraction, $F(1,144)=.02, p=.97, \eta^{2}=.00$. In regards to task enjoyment, the results were similar to the trends found for task performance where participants with a promotion focus enjoyed the task slightly more $(M$ $=2.88, S D=.97)$ than participants with a prevention focus $(M=2.77, S D=1.02)$ when there was no music. When music was played, there was a slight difference between means where participants with a promotion focus enjoyed the task slightly more $(M=$ $2.99, S D=.98)$ than participants with a prevention focus $(M=2.64, S D=.86)$ but this difference was not statistically significant. These results show that Hypothesis 2 was also not supported. 


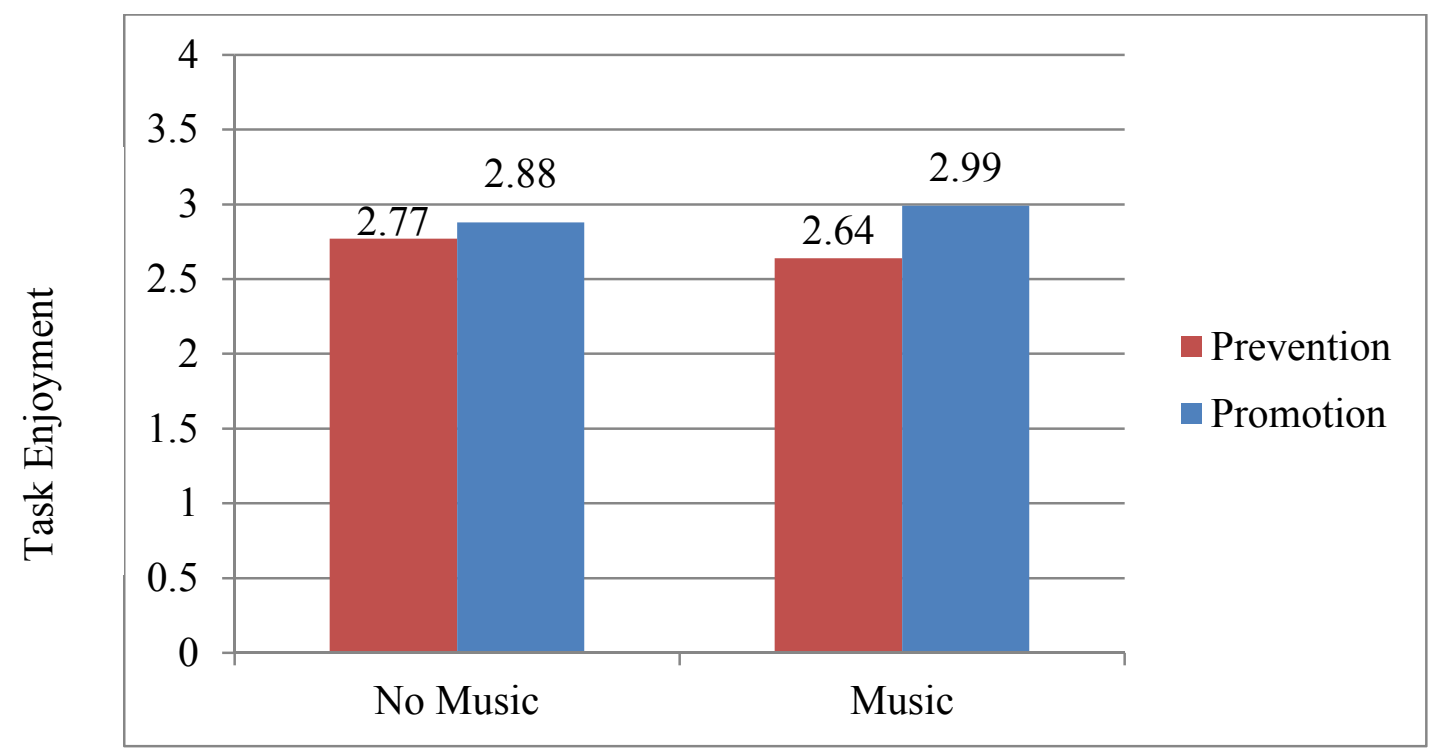

Figure 2. Task enjoyment by regulatory focus and distraction*

Note: *Results from one participant were excluded for having an incomplete enjoyment survey.

\section{Discussion}

With the advancements in technology, distractions like music, games, and the internet are all available at the touch of a button. This makes maintaining focus and productivity even more of a challenge. Phones, tablets, and laptops have become a necessity in day-to-day life enabling an irresistible temptation to be accessible 24/7. Music can also be downloaded onto smart phones and shared with others instantly by syncing to a speaker, making it unavoidable at times. By exercising strategies on selfregulation, people may be able to internalize distractions like these as motivators to push them towards their goal by any means necessary rather than as hurdles that keep them from their goal. Based on Regulatory Focus Theory, the current study tested the assumption that individuals with a prevention orientation (vs. a promotion orientation) would favor a means of ignoring popular music to focus on the goal at hand. Results of the current study did not support this assumption. 
Although the results were not statistically significant enough to draw any conclusions, there was an interesting trend in the findings which warrants further study on the matter. When music was played, participants with a promotion focus appeared to have slightly higher task performance and task enjoyment than participants with a prevention focus, which contradicted both hypotheses. Consistent with Hypothesis 2, when music was not played, participants with a promotion focus enjoyed the task slightly more than participants with a prevention focus. Overall, individuals with a promotion focus performed somewhat better and enjoyed the task somewhat more than their prevention-focused counterparts.

\section{Implications of the Study}

It has been debated whether music promotes or disrupts learning and task performance. It was proposed in the current study that an individual factor - regulatory focus - might contribute to a better understanding of the effect of music on performance. Even after taking into account this individual difference, the effect of music on task performance is still blurred. Prevention-focused individuals showed a slight decrease in performance when music was played than when music was not played, whereas promotion-focused individuals showed a slight increase in performance when music was played than when music was not played. Depending on the regulatory focus of the person, music may have some benefits for being played in the workplace or while studying but perhaps not while doing math. Overall, the results of the present study imply that it is unclear how music as a distraction influences performance as a function of a person's regulatory focus. 


\section{Limitations and Future Research}

The results of the present study did not significantly support either hypothesis. The lack of support could be attributed to several factors. First, unlike most studies that are based on Regulatory Focus Theory, there was no priming involved in the present study. Typically, participants are primed or exposed to a task that is meant to put them in either a promotion or prevention state of mind before they engage in the actual task being measured. Freitas et al. (2002) gave participants an essay that was meant to invoke their "ideal" or "ought" self-guides before they were administered the math problems. The main reason for omitting this common procedure was to reflect realistic circumstances in the workplace in everyday life. It is not likely that managers are able to prime their direct reports into a certain type of focus before giving them directions on their next project. Everyone has an innate or "chronic" regulatory focus; this was utilized in the study to determine the overall focus of each participant. However, priming participants may have been the key to strengthening the effects of regulatory fit and the role it plays when tempting distractions are involved. Perhaps researchers should look into this by conducting like experiments with and without priming. It would be interesting to test the extent priming has on performance outcomes.

Secondly, the lack of support for the hypotheses might have been due to the location of the study. The study was conducted in a room on campus between a classroom and a staff office. It was a challenge to conduct a truly silent condition for participants assigned to the control condition. Some typical interruptions included professors lecturing in a nearby classroom, other experimenters speaking loudly, students 
chattering incessantly, chairs scuffling, and doors slamming. It is possible that the brief instances of other people talking were more distracting to participants than music. Thus, the control condition may not have been a truly silent condition in some cases.

Therefore, more precaution is advised towards future researchers to ensure that the control condition is maintained.

Another limitation was not asking participants explicitly if they thought the music was distracting. From the follow-up survey, it was possible to determine if the music was interesting, but that did not imply that it was distracting. It would have helped to ask participants the question directly to know if the music was perceived as a distraction. Therefore, the lack of statistical significance might have been because participants in the distraction condition did not perceive the music as a distraction. Future research should re-evaluate the questions to ask when assessing task enjoyment.

Lastly, the use of math as the variable to determine task performance may have skewed the results simply because some people do not like math. Whether they were distracted or not, some participants may have performed poorly because they were not good at math. With the exclusion of mathematics, other types of tasks requiring complex, cognitive thought that are common in the workplace should be explored in future research. It was common for participants to be biased against math problems before they started the task. Perhaps, the relationship between popular music and Regulatory Focus theory could be tested in order to properly predict possible outcomes. For example, Van Dijk and Kluger (2011) noted that specific behavioral tendencies of people depended on their regulatory focus. Having a promotion focus fostered creativity, 
open-mindedness, risk taking, speed, production, and eagerness, whereas exhibiting a prevention focus related to conservative behavior, repetitiveness, attention-to-detail, error avoidance, accuracy, safety, and vigilance. The results of the current study may be attributed to the upbeat music intensifying the creativity level of those who were promotion-focused and therefore intensifying their engagement in the overall activity.

As previously mentioned, Doyle and Furnham (2012) found support for the tendency of creative individuals to listen to music while studying and report lower levels of distraction. On the same note, the attention-to-detail characteristic of those who were prevention-focused may have been their downfall as they may have been sensitive to even the slightest noise. More research in this area could prove beneficial and may even help explain the results of the current study. Also, it is interesting to note that out of the sample consisting of mainly young, college students, nearly two-thirds of them were found to have a promotion orientation. This gives possible insight into which regulatory focus may be more common among the current generation compared to older generations like those who may have grown up during times of war. Those interested in future research on the subject could look into the generational gap of what type of focus dominates society based on current events.

\section{Conclusion}

The current study's purpose was to measure the moderating role of regulatory fit on the effect of music as a distraction on task performance and enjoyment. It sought to test the assumption that individuals who are prevention-focused prefer a state of avoiding tempting distractions during goal-pursuit compared to those who are promotion-focused. 
Unfortunately, the current study did not provide support for this notion. Promotionfocused and prevention-focused individuals performed and enjoyed the task equally, regardless of the presence or absence of a distraction (i.e., music). Perhaps there was an assumption about promotion-focused individuals that was overlooked in regards to how they approach tempting distractions during goal pursuit. There may be a strong connection between music and people with a promotion focus which needs to be explored especially if it has the potential to positively influence task performance and enjoyment in the workplace. 


\section{References}

Bakker, A. B., Schaufeli, W. B., Leiter, M. P., \& Taris, T. W. (2008). Work engagement: An emerging concept in occupational health psychology. Work \& Stress, 22(3), 187-200. doi:10.1080/02678370802393649.

Cantor, J. (2013). Is background music a boost or a bummer? Psychology Today. Retrieved from http://www.psychologytoday.com/blog/conquering-cyberoverload/201305/is-background-music-boost-or-bummer.

Doyle, M., \& Furnham, A. (2012). The distracting effects of music on the cognitive test performance of creative and non-creative individuals. Thinking Skills and Creativity, 7(1), 1-7. doi:10.1016/j.tsc.2011.09.002.

Foerde, K., Knowlton, B. J., Poldrack, R. A., \& Smith, E. E. (2006). Modulation of competing memory systems by distraction. Proceedings of the National Academy of Sciences of the United States of America, 103(31), 11778-11783. doi:10.1073/pnas.0602659103.

Förster, J., \& Werth, L. (2009). Regulatory focus: Classic findings and new directions. In G.B. Moskowitz, H. Grant (Eds.), The Psychology of Goals, 349-420. New York, NY US: Guilford Press.

Fraser, C., \& Bradford, J. (2013). Music to your brain: Background music changes are processed first, reducing ad message recall. Psychology \& Marketing, 30(1), 6275. doi:10.1002/mar.20580.

Freitas, A. L., \& Higgins, E. T. (in press). Enjoying goal-directed action: The role of regulatory fit. Psychological Science.

Freitas, A. L., Liberman, N., \& Higgins, E. (2002). Regulatory fit and resisting temptation during goal pursuit. Journal of Experimental Social Psychology, 38(3), 291-298. doi:10.1006/jesp.2001.1504.

Freitas, A. L., Liberman, N., Salovey, P., \& Higgins, E. (2002). When to begin? Regulatory focus and initiating goal pursuit. Personality and Social Psychology Bulletin, 28(1), 121-130. doi:10.1177/0146167202281011.

Furnham, A., \& Bradley, A. (1997). Music while you work: The differential distraction of background music on the cognitive test performance of introverts and extroverts. Applied Cognitive Psychology, 11(5), 445-455. doi:10.1002/(SICI)1099-0720(199710)11:5<445::AID-ACP472>3.0.CO;2-R. 
Furnham, A., \& Strbac, L. (2002). Music is as distracting as noise: The differential distraction of background music and noise on the cognitive test performance of introverts and extraverts. Ergonomics, 45(3), 203-217.

doi:10.1080/00140130210121932.

Higgins, E. T. (1997). Beyond pleasure and pain. American Psychologist, 52, 1280-1013.

Higgins, E. T. (1998). Promotion and prevention: Regulatory focus as a motivational principle. In M.P. Zanna (Ed.), Advances in experimental social psychology, 30, 1-46. New York Academic Press.

Higgins, E.T. (2000). Making a good decision: Value from fit. American Psychologist, $55,12171230$.

Higgins, E.T. (2009). Regulatory fit in the goal-pursuit process. In G.B. Moskowitz, H. Grant (Eds.), The psychology of goals, 505-533. New York, NY, US: Guilford Press.

iPods and Learning: Not Always a Good Mix. (2006). T+D, 60(9), 14 .

Jarzebowski, A., Palermo, J., \& van de Berg, R. (2012). When feedback is not enough: The impact of regulatory fit on motivation after positive feedback. International Coaching Psychology Review, 7(1), 14-32.

Juneja, P. K. (2011). Auditory distractions in open office settings: A multi-attribute utility approach to workspace decision making. Dissertation Abstracts International Section A, 71(11-A), 3823.

Kämpfe, J., Sedlmeier, P., \& Renkewitz, F. (2011). The impact of background music on adult listeners: A meta-analysis. Psychology of Music, 39(4), 424-448. doi:10.1177/0305735610376261.

Lee, H. (2012). Effects of goal relations on self-regulated learning in multiple goal pursuits: Performance, the self-regulatory process, and task enjoyment. Asia Pacific Education Review, 13(2): 369-386. doi:10.1007/s12564-012-9216-y.

Lockwood, P., Jordan, C. H., \& Kunda, Z. (2002). Motivation by positive or negative role models: Regulatory focus determines who will best inspire us. Journal of Personality \& Social Psychology, 83(4), 854-864. doi:10.1037//00223514.83.4.854.

Merriam-Webster, n.d. Web. 15 Mar. 2013. "Distraction." Merriam-Webster.com. Retrieved from $<$ http://www.merriam-webster.com/dictionary/distraction>. 
Patterson, C. J., \& Mischel, W. (1976). Effects of temptation-inhibiting and taskfacilitating plans of self control. Journal of Personality and Social Psychology, 33(2), 209-217. doi:10.1037/0022-3514.33.2.209.

Pearsall, E. R. (1989). Differences in listening comprehension with tonal and atonal background music. Journal Of Music Therapy, 26(4), 188-197. doi:10.1093/jmt/26.4.188

Rodriguez, S. (2012). When school fits me: The role of regulatory fit in academic engagement and learning. Dissertation Abstracts International, 72(7-B), 4339.

Salamé, P., \& Baddeley, A. D. (1989). Effects of background music on phonological short-term memory. The Quarterly Journal Of Experimental Psychology A: Human Experimental Psychology, 41(1-A), 107-122. doi:10.1080/14640748908402355.

Scharf, F. R. (1995). Distraction potential in the office work environment. Dissertation Abstracts International, 56(5-B), 2919.

Shah, J., Higgins, T., \& Friedman, R. S. (1998). Performance incentives and means: How regulatory focus influences goal attainment. Journal of Personality And Social Psychology, 74(2), 285-293. doi:10.1037/0022-3514.74.2.285.

Shih, Y., Huang, R., \& Chiang, H. (2009). Correlation between work concentration level and background music: A pilot study. Work, 33(3), 329-333. doi:10.3233/WOR2009-0880.

Shih, Y., Huang, R., \& Chiang, H. (2012). Background music: Effects on attention performance. Work, 42(4), 573-578.

Smith, J. (2012). How to Ignore Distractions in the Workplace. Forbes.com, 19.

Spira, J. B. \& Feintuch, J. B. (2005) The cost of not paying attention: How interruptions impact knowledge worker productivity. Basex, Inc.

Too Much Technology is Cutting Productivity (2008). Work-Life Newsbrief \& Trend Report, 1.

Van Dijk, D., \& Kluger, A. N. (2011). Task type as a moderator of positive/negative feedback effects on motivation and performance: A regulatory focus perspective. Journal of Organizational Behavior, 32(8), 1084-1105. doi:10.1002/job.725.

Wolfe, D. E., (1983). Effects of Music Loudness on Task Performance and Self-Report of College-Aged Students. Journal of Research in Music Education, 31(3), 191-201. 
Woltin, K. A., Jonas, K. J. (2012). Thinking deadline: The impact of regulatory focus on deadline descriptions and deadline behavior. European Journal of Social Psychology, 42(3), 318-326. Doi:10.1002/ejsp.1860. 


\section{APPENDIX}

Questionnaire Items

Regulatory Focus (Higgins, 1997)

1. Compared to most people, are you typically unable to get what you want out of life?

2. Growing up, would you ever "Cross the line" by doing things that your parents would not tolerate?

3. How often have you accomplished things that got you "psyched" to work even harder?

4. Did you get on your parents' nerves often when you were growing up?

5. How often did you obey rules and regulations that were established by your parents?

6. Growing up, did you ever act in ways that your parents thought were objectionable?

7. Do you often do well at different things that you try?

8. Not being careful enough has gotten me into trouble at times.

9. When it comes to achieving things that are important to me, I find that I don't perform as well as I ideally would like to.

10. I feel like I have made progress toward being successful in my life.

11. I have found very few hobbies or activities in my life that capture my interest or motivate me to put effort into them.

\section{Scoring Key}

Regulatory Focus (Higgins, 1997)

Promotion score $=[(6-\mathrm{Q} 1)+\mathrm{Q} 3+\mathrm{Q} 7+(6-\mathrm{Q} 9)+\mathrm{Q} 10+(6-\mathrm{Q} 11)] / 6$

Prevention score $=[(6-\mathrm{Q} 2)+(6-\mathrm{Q} 4)+\mathrm{Q} 5+(6-\mathrm{Q} 6)+(6-\mathrm{Q} 8)] / 5$

Regulatory focus $=$ promotion - prevention 